\title{
Research on the Educational Function of Campus Football in the New Period
}

\author{
Hong-chun Jia ${ }^{1, a}$, Song-bo $\mathrm{He}^{1, \mathrm{~b}, *}$, Ting-ting $\mathrm{lv}^{2, \mathrm{c}}$ \\ ${ }^{1}$ Beihua University ,Jilin, China \\ ${ }^{2}$ Beihua University, College of physical education, Longteng innovation and entrepreneurship education base \\ *Corresponding author
}

Keywords: Campus football, Education function.

\begin{abstract}
China's football has been a great development, and campus football has become a major part of campus sports, and the comprehensive development of the campus plays a vital role. In the new era, how to effectively carry out campus football and how to strengthen the educational function of campus football has become an important issue in the development of campus football. This paper expounds the importance of the football school, and then puts forward some effective measures to strengthen the campus football education function under the new period, and according to the function of Education under the new era of football on campus, analyzes the various methods of strengthening the educational function of the campus football, school football career of our country healthy, sustainable and stable development has a certain guide.
\end{abstract}

\section{The good background of campus football development in the new period}

On March 16, 2015, the general office of the State Council issued the overall plan for China's reform and development of football. It has injected a shot in the arm released no doubt to the rapid development of China's football career. For campus football, as an important part of China's football industry, the announcement of China's overall development program of football reform also provides a good development background for its future development. In the educational function of campus football, the overall program of Chinese football reform and development was clearly indicated. It puts forward, "give full play to the educational function of football, and take campus football as the basic work of expanding the scale of football population, consolidating the foundation of football talents, improving the comprehensive quality of students and promoting the healthy growth of young people.". Let more young students love football and enjoy football, so that participating in football has become an effective way to experience and adapt to social rules and ethics."

\section{The educational function of campus football in the new period}

\subsection{Guiding function}

The formation of the campus football content, and the campus football culture environment. There is a direct guidance or a subtle influence on students. To cultivate the students' awareness of the spirit of collectivism, patriotism and fair competition, stimulate students' sense of national pride. At the same time. The campus football to promote spiritual civilization construction of students also have a good effect, the good atmosphere of the campus football culture can make students feel comfortable, cheerful, able to actively and consciously involved in football to.

\subsection{Condensation function}

The campus football can bring together the students and the school sports development. They have a sense of identity to the school sports development goals, and combining them as a member 
of the school's mission and sense of pride and sense of belonging to the campus formed by the integration of cohesion, individual development goal is the overall goal of the development of school physical education. At the same time, many of the campus football training program students are required to work together with cooperation. With long-term training can make mutual understanding, mutual help, deepen friendship between the students, but also enables them to establish the collective interests of the overall view, enhance the cohesion of the group. Cohesion derives from a universal sense of identity and understanding.

\subsection{Incentive function}

The motivation function of campus football is to emphasize, understand, respect and cherish students, strengthen students' learning motivation, and mobilize students' enthusiasm, initiative and creativity in football. Campus football puts students in a good psychological atmosphere and harmonious interpersonal environment. Bring them spiritual needs and satisfaction. At the same time, the campus football also set up a campus football culture for students to enjoy and create space. Provide and use stadium campus cultural activities hall, facilities and equipment in the background of the opportunity, make their beliefs can be realized with the sublimation of football.

\subsection{Education function}

In the new period, campus football reflects its educational function in a subtle way. On the one hand. It takes "compulsory course of a football lesson to the students in the form of spreading football knowledge and skills: on the other hand it offers a rich and colorful extracurricular football activities to improve students' knowledge structure, ability, personality, social needs, physical and mental health and to continue the development of socialization, inestimable, irreplaceable role.

\subsection{Intelligence promotion function}

The campus football plays an important role in promoting the development of students' intelligence. It can eliminate the brain fatigue accelerated students, make students mind clear, fresh and improve the efficiency of learning. At the same time, campus football can train students keen perception, flexible thinking ability, comprehensive observation ability, rich imagination, good attention and stable memory.

\subsection{Constraints and normative functions}

Under the new era, it is still necessary to manage schools according to the law. However, no matter how perfect the "hard" method of law is, it is impossible to restrict and regulate the students' thinking, psychology and behavior. Therefore, school governance needs the participation of "morality" and soft restriction. Campus football has an invisible restraining force, which can form a kind of soft restriction to restrict students' behavior, so as to make up for the restriction of various rules and regulations. This soft constraint can reduce the psychological impact of various hard constraints on students, so as to achieve unity, harmony and tacit understanding between students and teachers and schools.

\section{How to strengthen the educational function of campus football in the new period}

\subsection{Organization and management should be reasonable and standard}

At present, in our country the campus football activities, leading China's National Sports Bureau affiliated Chinese Football Association, is the highest level of management of Chinese football, can organize and carry out the campus football duties, specific organizational events and football activities and centralized training of athletes. This greatly limits the participation of the education sector, seriously affecting the healthy development of campus football in china. Therefore, in the new period, if campus football should give full play to its educational function, it is necessary to make the organization management reasonable and standard. For example, the Chinese Football Association can organize and manage the campus football activities of all schools in the city by setting up the city school office (the campus football office set up by the city's Ministry of 
education).

\subsection{The coach must ensure quantity and quality}

In the new period, if we want to achieve a healthy, sustained and steady development in campus football, the coach must ensure the quantity and quality. In other words, the development of campus football, strong teacher force is an indispensable prerequisite. At present, China's Ministry of education has made detailed plans, in 2015 will train 7000 campus football teachers from the national level. From this we can see that the state attaches great importance to the development of campus football. In this context, schools around China (from primary schools to universities) have also developed a training program for football coaches. To be exact, in the next few years, the number and quality of campus football coaches in China will be gradually alleviated.

\subsection{The education process must talk about methods}

The "overall" China football reform and development has just released soon, the campus football leadership in order to more rapid and efficient for the reform of the campus football will mainly work on improving the popularity of the campus football and football coach training work well. Yes, the work direction of these campus football leadership is correct. But it should improve in popularity and good coaching at the same time. Talk about methods, such as in-depth study of how to make a real football into the campus. How to make students love and participate in the campus football, how to make the campus football more comprehensive education students. Nowadays, many young students are crazy about online games and chatting online. Often in my spare time with mobile phones to play games, watch micro-blog, brush friends circle. For campus football, they are mostly running too tired, easy tanning, vulnerable to physical injury and other reasons to refuse. Therefore, the school should try to make some useful and creative design. Some of the football sports games as the starting point, through the game, let the students of the campus football program rules, basic knowledge, and then the introduction of other more professional content. In the new era, the realistic foundation of the campus football _ in China at present, the design of football games, the development of new campus football education method, let the students more easily accepted, it is particularly important.

\subsection{It's important to be supported by parents}

If we want to give full play to the educational function of campus football, it is very important for parents to be aware of it. Under the new era. More parents want their children to concentrate on learning cultural, theoretical and vocational skills. In football, the parents are not more understanding and support, they think that students play is worthless. In this regard, campus football leaders and coaches should do a good job of parents' ideological work, and explain to them the positive role played by campus football in the development of students' physical and mental health. When necessary, parents can be organized to watch and participate in campus football matches organized by schools, so that parents can feel the positive function and educational function of campus football.

\section{Conclusion}

In the new period, accompanied by the "China football reform and development overall program" released, the development of campus football in China ushered in a new historical opportunity, and its educational function is also more and more extensive and rich. However, campus football also faces many challenges in the process of its educational function. To this end, we must keep up with the times, and adhere to the principle of seeking truth from facts, and constantly deepen the reform, to the greatest extent to promote the all-round development of China's campus football. To recognize the educational value of campus football, to realize the importance of campus football, to develop its function is of far-reaching significance. The role of campus football is not immediate, after all, a player's growth should be in about 10 years, but what we need to do is to adhere to and continue to explore, and its future path is bright. 


\section{Acknowledgements}

This paper is a research project of Beihua University students' innovation project, horizontal topi c: Dragon Boat land training equipment (NO:201602014).

\section{References}

[1] Li Jixia, He Zhilin, Dong Zhongming, Xu Yangcai. Development bottleneck and Breakthrough Strategy of national youth football activities.[J]. Journal of Shanghai Institute of Physical Education, 2012 (05)

[2] Wang Ge. Research on the current situation, problems and Countermeasures of campus football activities in China.[J]. Journal of Shenyang Sport University, 2011 (04)

Zhu Chao van [3], Qinghui..2016 value of education and development strategy of.[J]. teaching and management of the campus football (18).

[4], Sun Guangxu, Li Lixin. Research on the construction of hierarchical system and flexible management of campus football teaching contents [J]. Journal of Yangtze University (Family Science Edition), 2016, 04:69-72

[5]] Liao Xin. On Campus Soccer.[J]. Sichuan sports science, 2010, (2):120 - 122.

[6] Yan Zhongjie and the predicament and outlet of campus football activities in Shanghai. [J]. sports research, 2011, 32 (1):80 - 83.

[7] Li Weidong. Investigation and analysis of the youth football activities on campus in China. [J]. Journal of Shanghai Institute of Physical Education, 2011, 35 (5),:22 - 25.

[8] Mao Mao. The cultivation of football awareness in college football teaching. [J]. sports world (Academic Edition), 2016, 04:131-132 